\title{
ИССЛЕДОВАНИЕ ВЛИЯНИЯ ВИДА СЫРА НА ОРГАНОЛЕПТИЧЕСКИЕ И ФИЗИКО-ХИМИЧЕСКИЕ СВОЙСТВА КОНО-ПИЦЦЫ
}

\section{A.V. Barsukova, A.V. Borisova \\ THE STUDY OF THE INFLUENCE OF CHEESE ON ORGANOLEPTIC AND PHYSICAL AND CHEMICAL PROPERTIES OF KONO-PIZZA}

Барсукова Анна Владимировна - студ. 4-го курса Самарского государственного технического университета, г. Самара. E-mail: Anyuta-barsukova.barsukova@yandex.ru Борисова Анна Викторовна - канд. техн. наук, доц. каф. технологии и организации общественного питания Самарского государственного технического университета, г. Самара.

E-mail: Anna_borisova_63@mail.ru

Цель исследования - изучение влияния разновидности сыра на органолептические и фризико-химические показатели качества конопиццы и выбор наиболее подходящего вида сыра в производстве таких изделий. В задачи исследования входило: 1) определение и сравнительный анализ фризико-химических и технологических (температура плавления и cmeпень растяжимости) параметров трех видов сыров; 2) исследование влияния вида сыра на фризико-химические, технологические и органолептические свойства коно-пиццы; 3) обоснование выбора сыра для рецептуры конопиццы по результатам исследования. В качестве объектов исследования были отобраны три вида сыров: сыр «Российский» развесной, брусок; сыр моцарелла шарообразный в рассоле; сыр моцарелла для пициы развесной, брусок. Коно-пициа готовилась по традиционной рецеnтуре пищцы «Маргарита» с томатным соусом. Исследованием установлено, что моцарелла в рассоле образует более длинные нити на коно-пицее, чем сыр «Российский» и моцарелла для пициы, длина нитей которых при растяжении оказалась примерно одинаковой. Это свидетельствует о том, что чеддеризация сыра моцарелла мало влияет на дальнейшее плавление сыра при выпечке, и что сыр «Российский» также пригоден к использо-
Barsukova Anna Vladimirovna - 4-Year Student, Samara State Technical University, Samara. E-mail: Anyuta-barsukova.barsukova@yandex.ru

Borisova Anna Victorovna - Cand. Techn. Sci., Assoc. Prof., Chair of Technology and Organization of Public Catering, Samara State Technical University, Samara.

E-mail: Anna_borisova_63@mail.ru

ванию в пищце. Установлена температура плавления всех сыров, она составляет 40$60{ }^{\circ} \mathrm{C}$, нагревание сверх указанной температуры приводит к растеканию сыров. При 70$75{ }^{\circ} \mathrm{C}$ происходит полное плавление сыров. Также определена массовая доля сухих веществ в исследуемых сырах, и выявлено, что все сыры соответствуют нормам. Методом попарного сравнения и ранжирования определен коэффрициент конкордации в органолептической оценке изделий, и вьявлено, что наилучшими свойствами обладает коно-пициа с сыром «Российский», а наихудшими - конопициа с моцареллой в рассоле. Коэфрфициент согласованности мнений экспертов составил 0,7. Мнения экспертов можно считать согласованными и их необходимо учитывать при определении оптимальной рещептуры для приготовления коно-пиццы.

Ключевые слова: коно-пищиа, сыр для пиццы, общественное питание, сыр «Российский», моцарелла.

The research objective was studying the influence of the kind of cheese on organoleptic and physical and chemical indicators of the quality of Kono-pizza and the choice of the most suitable type of cheese in cooking such products. The research included the problems: 1) the definition and 
comparative analysis of physical and chemical and technological (temperature of melting and degree of tensile properties) parameters of three types of cheeses; 2) the research of the influence of the type of cheese on physical and chemical, technological and organoleptic properties of Kono-pizza; 3) the justification of the choice of cheese for Konopizza compounding by the results of the research. As the objects of the research three types of cheeses were selected: "Russian" cheese sold by weight, whetstone; spherical mozzarella cheese in brine; mozzarella cheese for pizza sold by weight, whetstone. Kono-pizza was cooked by a traditional compounding of "Margarita" pizza with tomato sauce. In the study it was established that the mozzarella in brine formed longer strands on Konopizza, than "Russian" cheese and the mozzarella for pizza which length of strands at stretching was approximately identical. It testified that mozzarella cheese chedderization had little influence on further cheese melting in the pastries and that "Russian" cheese was also suitable for using in pizza. The temperature of melting of all cheeses was established; it made $40-60{ }^{\circ} \mathrm{C}$, heating over specified temperature led to cheese spreading. At $70-75^{\circ} \mathrm{C}$, the cheeses melted completely. The mass fraction of solids in studied cheeses was also defined and it revealed that all the cheeses had met the standards. The method of pairwise comparison and ranging determined concordance coefficient in organoleptic assessment of the products and it was re- vealed that the best properties had "Russian" cheese in Kono-pizza, and the worst - Kono-pizza with mozzarella in brine possessed. The expert consensus rate was 0.7. The opinions of experts can be considered coordinated and they need to be used when determining an optimum compounding for preparation of Kono-pizza.

Keywords: Kono-pizza, cheese for pizza, public catering, Russian cheese, mozzarella.

Введение. В последние годы быстро и стабильно развивается индустрия быстрого питания - пиццерии, бургерные и другие заведения фастфуда, ориентированные на изготовление продукции, как правило, узкого ассортимента, изготовленной из полуфабрикатов высокой степени готовности и не требующей длительного приготовления: гамбургер, сэндвич, пицца и т. д. $[1,2]$.

Сегодня огромной популярностью обладает доставка еды на дом. Как показали исследования [3], еду на дом заказывают от 40 до 57 \% россиян (в зависимости от региона). При изучении распределения потребительского спроса выявлено, что 56 \% участников опроса предпочитают пиццу, $37 \%$ респондентов заказывают суши и роллы, 18 \% опрошенных выбирают шашлыки и другие виды продукции, приготовленной на гриле (рис. 1) [3].

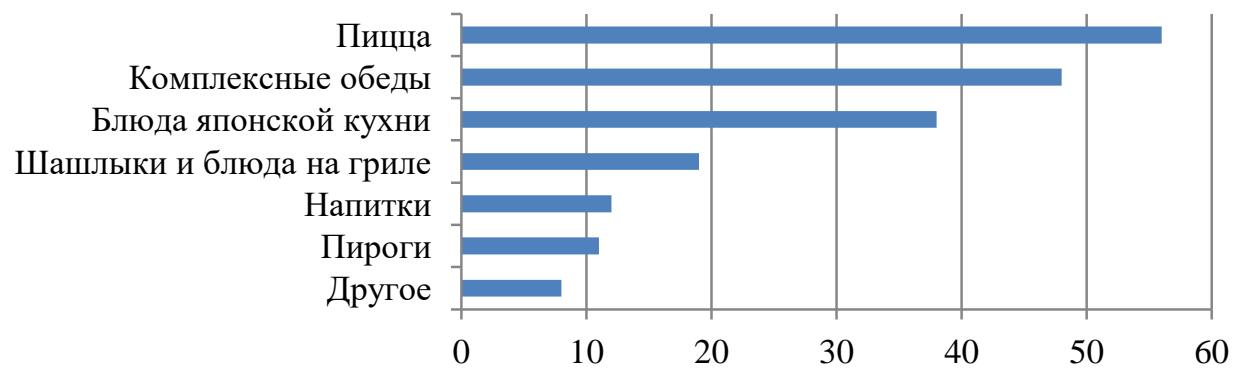

Puс. 1. Изделия (блюда), доставляемье на дом, пользующиеся наибольшей популярностью, \% [3]

Пицца является одним из наиболее популярных изобретений в сфрере питания. ConoPizza это особый вид пиццы, начинка которой не лежит на поверхности теста, а размещается внутри конуса из теста. Именно слово «конус» дало название этой пицце, в связи с тем, что по- итальянски конус пишется как «сопо». В России такая пицца называется «коно-пицца» либо «пицца в конусе», иногда называют «пицца в стаканчике». Впервые пиццу в виде конуса изготовил американец Эсс Джозеф в 1983 г., однако признание такой формы пиццы произошло лишь 
в 2003 г. [4]. Начинки для коно-пицц могут быть самыми разнообразными - от обычных сырнотоматных до сладких и фруктовых [5].

Калорийность и вкус пиццы зависит от сыра, используемого в начинке. Сыры для пиццы классифицируют по содержанию влаги: на твердые, полутвердые, мягкие и рассольные. Сыры с чеддеризацией и термомеханической обработкой сырной массы широко используются в производстве пиццы, так как имеют высокие пластичные свойства, а также способны вытягиваться в нити при нагревании выше $60^{\circ} \mathrm{C}$. Эти свойства ценятся пицца-мейкерами, поэтому для приготовления пиццы используется в основном сыр моцарелла как основной представитель сыров этой группы [6-8].

Цель исследования: изучение влияния разновидности сыра на органолептические и физикохимические показатели качества коно-пиццы и выбор наиболее подходящего вида сыра в производстве таких изделий.

В задачи исследования входило: 1) определение и сравнительный анализ фризикохимических и технологических (температура плавления и степень растяжимости) параметров трех видов сыров; 2) исследование влияния вида сыра на физико-химические, технологические и органолептические свойства коно-пиццы; 3) обоснование выбора сыра для рецептуры коно-пиццы по результатам исследования.

Материалы и методы исследования. Для определения влияния на органолептические и физико-химические свойства коно-пиццы с сыром были изучены следующие разновидности сыров: 1) сыр российский «Valio» развесной, брусок; 2) сыр моцарелла в рассоле «Galbani», шарики; 3) сыр моцарелла сухая для пиццы «Unagrande», развесная в бруске. Коно-пицца готовилась по базовой рецептуре пиццы «Маргарита» [9].

В сырах определяли массовую долю влаги и сухих веществ по ГОСТ 3626-73. Температуру плавления определяли при плавлении навески сыра на водяной бане с помощью термощупа. Степень растяжимости сыра определяли с помощью линейки при нагревании образца до $60{ }^{\circ} \mathrm{C}$ и вытягивании нитей до их разрыва.

В готовых коно-пиццах определяли содержание сухих веществ и влажность по ГОСТ 590073. Органолептические показатели коно-пицц были исследованы попарным методом ранжирования [10].

Для установления согласованности мнений экспертов был вычислен коэффрициент конкордации по формуле

$$
W=\frac{12 \cdot S}{n^{2} \cdot\left(m^{3}-m\right)}
$$

где W - коэфффициент конкордации; S - квадрат отклонения от среднего арифметического рангов; $\mathrm{N}$ - количество экспертов; $\mathrm{m}$ - количество исследуемых образцов.

Все опыты были проведены в трехкратной повторности.

Результаты исследования и их обсуждение. Результаты исследования физикохимических показателей сыров представлены в таблице 1.

\section{Физико-химические и технологические свойства исследуемых сыров}

\begin{tabular}{|l|c|c|c|}
\hline \multicolumn{1}{|c|}{ Исследуемый параметр } & $\begin{array}{c}\text { Сыр } \\
\text { «Российский» }\end{array}$ & $\begin{array}{c}\text { Сыр моцарелла } \\
\text { в рассоле }\end{array}$ & $\begin{array}{c}\text { Сыр моцарелла } \\
\text { сухая }\end{array}$ \\
\hline Влажность, \% & 33,3 & 55,6 & 30,0 \\
\hline Массовая доля сухих веществ, \% & 66,7 & 44,4 & 70,0 \\
\hline Предел растяжимости, см & 32 & 49 & 33 \\
\hline $\mathrm{T}_{\text {плав }}{ }^{\circ} \mathrm{C}$ & 44 & 44 & 44 \\
\hline
\end{tabular}

Из данных таблицы можно сделать вывод о том, что моцарелла в рассоле имеет наибольшее содержание влаги. Согласно ГОСТ 322602013, влажность сыра «Российский» не должна превышать 43 \%, поэтому данный сыр соответствует норме. Сыр моцарелла сухая содержит только 30 \% влаги, что в 1,85 раз меньше, чем в сыре моцарелла в рассоле. 
У исследуемых сыров был определен предел растяжимости. Из результатов таблицы 1 видно, что наиболее высокий предел растяжимости у сыра моцарелла в рассоле, наименьший предел - у сыра «Российский». Данный фракт можно объяснить тем, что при производстве сыра моцарелла используют стадию нагревания и вытягивания сырной массы в конце изготовления сыра. Во время вытягивания аморфный параказеиновый матрикс сырного сгустка перестраивается и ориентируется в виде почти параллельных параказеиновых волокон, в которые включены глобулы жира и несвязанной сыворотки. Благодаря такой переориентации, сырный сгусток приобретает способность расслаиваться на нити и вытягиваться при нагревании на пицце [11]. Особенностью технологии производства сыра «Российский» является повышенное кислотообразование. Однако величина $\mathrm{pH}$ сыра «Российский» выше, чем у моцареллы (4,6 против 4,2), вследствие этого при плавлении он формирует более короткие нити.
Также можно отметить, что сыр моцарелла сухая для пиццы имеет длину нитей, схожую с сыром «Российским», хотя изготовление этого сыра также должно включать стадии нагревания и вытягивания. Вполне вероятно, это связано с нарушением технологии изготовления и более низкой кислотностью сырной массы, а также с пониженной массовой долей влаги по отношению к моцарелле в рассоле.

Температура плавления всех сыров одинакова (табл. 1). Сыры начинают плавиться при $44{ }^{\circ} \mathrm{C}$, а при нагревании выше этой температуры они разжижаются, при $70-75^{\circ} \mathrm{C}$ расплавляются полностью.

Дальнейшим этапом стало изучение конопицц с исследуемыми сырами. Внешний вид готовых изделий с сыром представлен на рисунке 2.

Результаты определения влажности и содержания сухих веществ представлены в таблице 2.
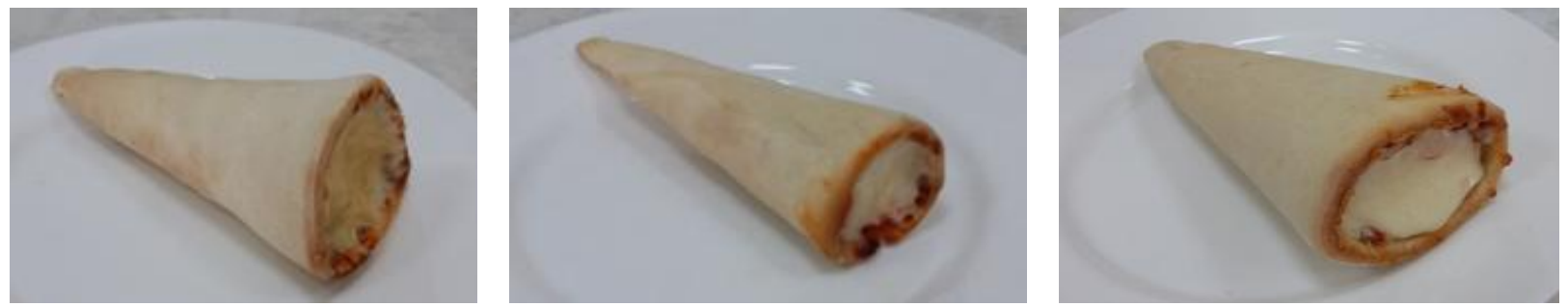

Рис. 2. Внешний вид готовых изделий

Таблица 2

Влажность и содержание сухих веществ в исследуемых коно-пиццах

\begin{tabular}{|l|c|c|c|}
\hline \multirow{2}{*}{\multicolumn{1}{|c|}{ Показатель }} & \multicolumn{3}{|c|}{ Коно-пицца } \\
\cline { 2 - 4 } & $\begin{array}{c}\text { С сыром } \\
\text { «Российским» }\end{array}$ & $\begin{array}{c}\text { С моцареллой } \\
\text { в рассоле }\end{array}$ & $\begin{array}{c}\text { С моцареллой } \\
\text { сухой }\end{array}$ \\
\hline Влажность, \% & 42,9 & 34,8 & 46,7 \\
\hline Содержание сухих веществ, \% & 57,1 & 65,2 & 53,3 \\
\hline
\end{tabular}

Комиссией из пяти человек был проведен органолептический анализ трех исследуемых коно-пицц методом ранжирования. Была произведена оценка по четырем показателям: внешний вид, вкус, аромат, консистенция.
Расчет степени согласованности мнений пяти экспертов представлен в таблице 3.

Органолептическая оценка готовых изделий представлена в таблице 4. 
Расчет степени согласованности мнений пяти экспертов

\begin{tabular}{|c|c|c|c|c|c|c|c|c|}
\hline Образец & 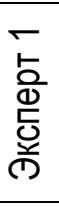 & 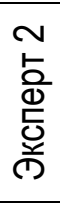 & 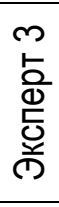 & 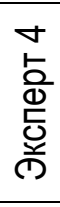 & 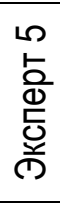 & $\begin{array}{l}\text { Сумма } \\
\text { рангов }\end{array}$ & $\begin{array}{c}\text { Отклонение } \\
\text { от среднего } \\
\text { арифметиче- } \\
\text { ского } \\
\end{array}$ & $\begin{array}{c}\text { Квадрат } \\
\text { отклонения } \\
\text { от среднего } \\
\text { арифмметического }\end{array}$ \\
\hline $\begin{array}{l}\text { Коно-пицца с сыром } \\
\text { «Российский» }\end{array}$ & 2 & 2 & 2 & 2 & 2 & 10 & 5 & 25 \\
\hline $\begin{array}{l}\text { Коно-пицца с сыром } \\
\text { моцарелла в рассоле }\end{array}$ & 0 & 0 & 0 & 0 & 0 & 5 & 0 & 0 \\
\hline $\begin{array}{l}\text { Коно-пицца с сыром } \\
\text { моцарелла для пиццы }\end{array}$ & 1 & 1 & 1 & 1 & 1 & 0 & -5 & 25 \\
\hline \multicolumn{6}{|l|}{ Общая сумма рангов } & 15 & & \multirow{3}{*}{50} \\
\hline \multicolumn{6}{|c|}{ Среднее арифметическое рангов } & 5 & & \\
\hline \multicolumn{8}{|c|}{ Сумма квадратов отклонения от среднего арифметического } & \\
\hline
\end{tabular}

Таблица 4

Органолептическая оценка готовых изделий

\begin{tabular}{|c|c|c|c|}
\hline Пицца & Показатель & Комментарий & Балл \\
\hline \multirow{4}{*}{ 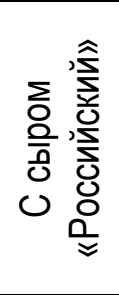 } & $\begin{array}{l}\text { Внешний } \\
\text { вид }\end{array}$ & $\begin{array}{l}\text { Конус имеет бледно-песочный цвет, сыр ярко-желтый, в раз- } \\
\text { резе имеется много начинки }\end{array}$ & 1 \\
\hline & Аромат & $\begin{array}{l}\text { Сильно выражен аромат томатов, также хорошо выражен аро- } \\
\text { мат сыра и базилика }\end{array}$ & 4 \\
\hline & Текстура & Хрустящее тесто, густой соус, сыр тягучий & 1 \\
\hline & Вкус & Ярко выраженный вкус томатов, сыра и базилика & 2 \\
\hline \multirow{4}{*}{ 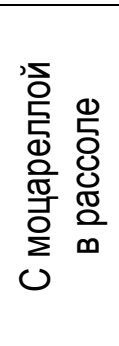 } & $\begin{array}{l}\text { Внешний } \\
\text { вид }\end{array}$ & $\begin{array}{l}\text { Конус имеет бледно-песочный цвет, сыр бледно-желтый, } \\
\text { в разрезе имеется много начинки }\end{array}$ & 1 \\
\hline & Аромат & $\begin{array}{l}\text { Ярко выраженный аромат томатов и базилика, аромат сыра } \\
\text { слабо выражен }\end{array}$ & 2 \\
\hline & Текстура & Тесто хрустящее, сыр плотный, соус густой & 1 \\
\hline & Вкус & $\begin{array}{l}\text { Сильно выражен вкус томатов и базилика, вкус сыра слабо } \\
\text { выражен }\end{array}$ & 1 \\
\hline \multirow{4}{*}{ 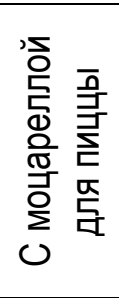 } & $\begin{array}{l}\text { Внешний } \\
\text { вид }\end{array}$ & $\begin{array}{l}\text { Конус имеет бледно-песочный цвет, сыр желтый, в разрезе } \\
\text { имеется много начинки }\end{array}$ & 1 \\
\hline & Аромат & $\begin{array}{l}\text { Ярко выраженный аромат томатов и базилика, аромат сыра } \\
\text { слабо выражен }\end{array}$ & 3 \\
\hline & Текстура & Тесто более толстое, плотное, не хрустящее & 1 \\
\hline & Вкус & Сильно выражен вкус томатов и базилика, немного сыра & 1 \\
\hline
\end{tabular}

При органолептическом анализе было выявлено, что коно-пицца с сыром «Российский» обладает наилучшими вкусовыми и ароматическими характеристиками, а коно-пицца с моцареллой в рассоле - худшими.

При расчете степени согласованности мнений экспертов вычислен коэффицииент конкордации, равный 1.
Таким образом, мнения экспертов можно считать согласованными и их нужно учитывать при определении оптимальной рецептуры для приготовления коно-пиццы.

Выводы. В результате изучения фризикохимических и органолептических характеристик трех видов коно-пиццы выявлено, что все три образца обладают удовлетворительными для 
потребителя характеристиками по органолептическим и физико-химическим показателям: хорошим вкусом и физико-химическими показателями в пределах нормы [12, 13]. Однако конопицца с сыром «Российский» имеет наилучшие вкус и аромат по результатам органолептической оценки. Замена сыра моцарелла на сыр «Российский» в производстве пиццы позволит расширить ассортимент изделий и снизить их себестоимость.

\section{Литература}

1. Захарова И.И., Крылова Р.В. История развития заведений фастфуда в России // Инновационная наука. - 2016. - № 3. - С. 98-102.

2. Карх Д.А., Чугунова О.В., Гращенков Д.В. Особенности логистической деятельности по доставке изделий (блюд) на дом // Вестник ЮУрГУ. - 2014. - Т. 8, № 2. - С. 167-172.

3. Султаева Н.Л. Особенности функционирования и проектирования предприятий быстрого обслуживания // Сервис в России и за рубежом. - 2016. - № 1 (20). - С. 183192.

4. Что такое cono-pizza. - URL: https://www.tokyo-city.ru/interesting/Etointeresno/CHto-takoe-Cono-Pizza.

5. Маслякова Е.В. Твоя пиццерия. - М.: Вече, 2002. - 288 C.

6. Dai S., Jiang F., Shah N.P., Corke H. Functional and pizza bake properties of Mozzarella cheese made with konjacglucomannan as a fat replacer // Food Hydrocolloids, 2019, vol. 92, pp. 125-134. DOI: https://doi.org/10.1016/ j.foodhyd.2019.01.045.

7. Berta M., Muskens E., Schuster E., Stading M. Rheology of natural and imitation mozzarella cheese at conditions relevant to pizza baking // International Dairy Journal, 2016, vol. 57, pp. 34-38. DOI: 10.1016/j.idairyj.2016.02.038.

8. Моисеев Н.Ю., Сучкова Е.П. Методы определения способности к растягиванию сыров для пиццы // Изв. высших учебных заведений. Пищевая технология. - 2016. - № 5-6 (353-354). - C. 80-85.

9. Пицца и рецепты. - URL: https://pizza rezept.ru/recipe/picca-margarita.
10. Сидоренко Г.А., Федотов В.А., Медведев П.В. Научно-исследовательская практика: учеб. пособие. - Оренбург: Изд-во ОГУ, 2017. $98 \mathrm{c}$.

11. МакСуини П.Л.Г. Практические рекомендации сыроделам. - СПб.: Профессия, 2010. $374 \mathrm{c}$.

12. СП 2.3.6.1079-01. Санитарно-эпидемиологические требования к организациям общественного питания, изготовлению и оборотоспособности в них пищевых продуктов и продовольственного сырья. - М., 2002. $96 \mathrm{c}$.

13. Методические указания по лабораторному контролю качества продукции общественного питания (рекомендованы Минторгом СССР 1-40/3805 от 11.11.1991). - М., 1991. $145 \mathrm{c}$.

\section{Literatura}

1. Zaharova I.I., Krylova R.V. Istoriya razvitiya zavedenij fastfuda v Rossii // Innovacionnaya nauka. - 2016. - № 3. - S. 98-102.

2. Karh D.A., CHugunova O.V., Grashchenkov D.V. Osobennosti logisticheskoj deyatel'nosti po dostavke izdelij (blyud) na dom // Vestnik YUUrGU. - 2014. - T. 8, № 2.S. 167-172.

3. Sultaeva N.L. Osobennosti funkcionirovaniya i proektirovaniya predpriyatij bystrogo obsluzhivaniya /I Servis V Rossii i za rubezhom. - 2016. - № 1 (20). - S. 183-192.

4. CHto takoe cono-pizza. - URL: https://www.tokyo-city.ru/interesting/Etointeresno/CHto-takoe-Cono-Pizza.

5. Maslyakova E.V. Tvoya picceriya. - M.: Veche, 2002. - $288 \mathrm{~s}$.

6. Dai S., Jiang F., Shah N.P., Corke H. Functional and pizza bake properties of Mozzarella cheese made with konjacglucomannan as a fat replacer // Food Hydrocolloids, 2019, vol. 92, rr. 125-134. DOI: https://doi.org/10.1016/ j.foodhyd.2019.01.045.

7. Berta M., Muskens E., Schuster E., Stading M. Rheology of natural and imitation mozzarella cheese at conditions relevant to pizza baking // 
International Dairy Journal, 2016, vol. 57, 11. MakSuini P.L.G. Prakticheskie rekomendaci rr. 34-38. DOI: 10.1016/j.idairyj.2016.02.038. syrodelam. - SPb.: Professiya, 2010. - $374 \mathrm{~s}$.

8. Moiseev N.Yu., Suchkova E.P. Metody opredeleniya sposobnosti $\mathrm{k}$ rastyagivaniyu syrov dlya piccy // Izv. vysshih uchebnyh zavedenij. Pishchevaya tekhnologiya. 2016. - № 5-6 (353-354). - S. 80-85.

9. Picca i recepty. - URL: https://pizzarezept.ru/ recipe/picca-margarita.

10. Sidorenko G.A., Fedotov V.A., Medvedev P.V. Nauchno-issledovatel'skaya praktika: ucheb. posobie. - Orenburg: Izd-vo OGU, 2017. -98 s.

12. SP 2.3.6.1079-01. Sanitarno-epidemiologicheskie trebovaniya $k$ organizaciyam obshchestvennogo pitaniya, izgotovleniyu i oborotosposobnosti $v$ nih pishchevyh produktov i prodovol'stvennogo syr'ya. - M., 2002. $-96 \mathrm{~s}$.

13. Metodicheskie ukazaniya po laboratornomu kontrolyu kachestva produkcii obshchestven nogo pitaniya (rekomendovany Mintorgom SSSR 1-40/3805 ot 11.11.1991). - M., 1991. $145 \mathrm{~s}$. 